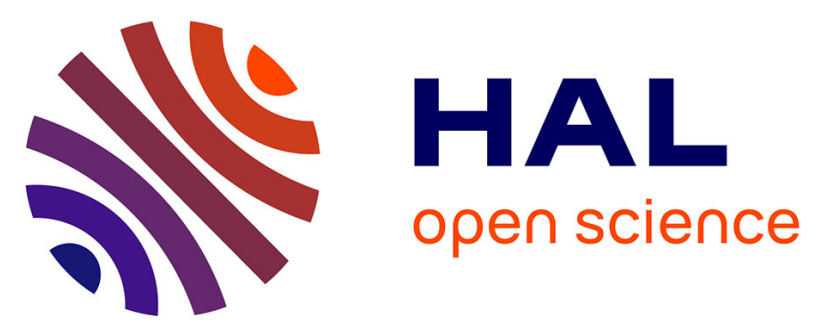

\title{
Investigation of the possible origins of the differences in mechanical properties of hemp and flax fibres: a numerical study based on sensitivity analysis
}

\author{
Alessandra del Masto, Frédérique Trivaudey, Violaine Guicheret, Vincent
} Placet, Lamine Boubakar

\section{To cite this version:}

Alessandra del Masto, Frédérique Trivaudey, Violaine Guicheret, Vincent Placet, Lamine Boubakar. Investigation of the possible origins of the differences in mechanical properties of hemp and flax fibres: a numerical study based on sensitivity analysis. Composites Part A: Applied Science and Manufacturing, 2019, 124, pp.105488 (13). hal-02370546

\section{HAL Id: hal-02370546 \\ https://hal.science/hal-02370546}

Submitted on 25 Oct 2021

HAL is a multi-disciplinary open access archive for the deposit and dissemination of scientific research documents, whether they are published or not. The documents may come from teaching and research institutions in France or abroad, or from public or private research centers.
L'archive ouverte pluridisciplinaire HAL, est destinée au dépôt et à la diffusion de documents scientifiques de niveau recherche, publiés ou non, émanant des établissements d'enseignement et de recherche français ou étrangers, des laboratoires publics ou privés.

\section{(ㄷ)(1) $\$$}

Distributed under a Creative Commons Attribution - NonCommerciall 4.0 International 


\title{
Investigation of the possible origins of the differences in mechanical properties of hemp and flax fibres : a numerical study based on sensitivity analysis
}

\author{
A. Del Masto*, F. Trivaudey*, V. Guicheret-Retel*, V. Placet*, L. Boubakar* \\ Univ. Bourgogne Franche-Comté \\ FEMTO-ST Institute \\ CNRS/UFC/ENSMM/UTBM \\ Department of Applied Mechanics \\ 24 rue de l'Epitaphe, 25000 Besançon, France
}

\begin{abstract}
Despite the great similarities in the physical and chemical properties of flax and primary hemp fibres, literature generally reports differences in their average tensile properties. This work proposes a numerical investigation of the relationships between the morphological, biochemical and cell wall features, along with their variability, and the mechanical properties of flax and hemp fibres. A previously developed 3D micromechanical model of plant fibre is used to carry out a sensitivity analysis. Results show that the difference observed in the average tensile properties of flax and hemp fibres is partly due to the differences in scattering of some their morphological and ultrastructural properties. Despite a similar mean value, the reduced variability in the flax fibre features, seems to lead to higher average tensile properties.

Keywords: A. Natural fibres, B. Mechanical properties, C. Computational modelling, C. Statistical properties/methods
\end{abstract}

\section{Introduction}

Plant fibres have for long been considered as attractive materials, especially in the textile industry. However, during the last century, remarkable results have been achieved worldwide in green technology in the field of materials science through the development of high-performance composite materials reinforced by plant fibres [1,2]. Fibres derived from plants, such as hemp, flax, jute and alfa fibres appear suitable for many industrial applications [3] thanks to their high specific properties, especially when compared to those of glass fibres $[4,5]$.

\footnotetext{
* Corresponding author

Email address: alessandra.delmasto@gmail.com (A. Del Masto)
} 
Flax and hemp are the most widely cultivated plants providing bast fibres for composite applications in Europe. They are also among the most studied natural fibres from a mechanical point of view [6]. Historical [7] and recent works [8] show that the cell wall is very similar between flax and hemp fibres, in terms of layers and sub-layers (number, thicknesses), biochemical composition, cellulose crystallinity index, cellulose microfibrils angle (MFA). Some differences can also be observed in the literature but the scattering in properties observed for each type of fibres is also very broad and make the comparison inconclusive [6]. The scattering in such parameters for a fibre type is mainly attributed to the origin, variety, cultural, climatic, maturity and processing parameters and also to the analytical techniques $[9,10]$.

Only the fibrillary orientation is different: S-twist for flax and Z-twist for hemp [11].

The shape of the cross-section of the fibre as well as its area can differ between flax and hemp. Flax has generally a reduced lumen area and the shape of its internal and external contour lines is closer to a perfect circle when compared to hemp. Flax fibres tend to have a smaller diameter than hemp fibres $[12,13,14,11]$. Anyway, these features are also highly dependent to cultural and climatic parameters. By the way, Bergfjord and Holst [11] pointed out the attempts have been made to identify and distinguish bast fibres (in particular flax, hemp, ramie and jute) in both archeology and criminology by applying surface characteristics, chemical composition and cross section size and shape, but none of these methods can be said to be conclusive.

The fibre length is generally higher for flax than for hemp [8].

The mechanical properties of their wall is also comparable. It was characterized by Peak-Force Quantitative Nano-Mechanical property mapping [15, 16]. Bourmaud et al. [15] report an elastic modulus around 22-23 GPa for hemp fibre wall while Goudenhooft et al. [16] obtained values of stiffness around 17-18 GPa in the case of flax.

Despite these similarities, they also generally exhibit differences in their tensile properties, and their global tensile behaviour. Indeed, despite a relatively similar structure and biochemical composition, flax fibres generally have slightly better tensile properties than hemp fibres [17], especially in terms of tensile strength and stiffness. On the other hand, they reach a smaller tensile strain at failure than hemp [18].

Regarding the biochemical composition, flax is characterized by a high percentage of crystalline cellulose, while the mass fraction of cellulose constituting it is in average lower compared to hemp $[19,20]$.

The ultrastructure of these two fibres, defined in particular by the microfibrillar angle (MFA), is also comparable [21].

Concerning the variability of the morphological, ultrastructural and biochemical composition characteristics, these two fibres have comparable scattering for almost all the parameters, except for the 
diameter and the fraction of crystalline cellulose: in this case the variability observed for hemp is at least twice the variability reported for flax [22, 23].

In view of the above, it could be hypothesized that the observed differences in the average mechanical properties of these two similar fibres are indeed led by the diversity in ranges of the parameters characterising their morphology, ultrastructure and composition.

The relationship between morphology, ultrastructure and composition of the fibre wall and tensile behaviour of plant fibre is still not well understood. Many studies are available in the literature concerning the factors affecting the mechanical properties of flax and hemp [24, 25, 26]. However, to the best of our knowledge, any of them takes into account the possible interactions between a more complex fibre morphology, the ultrastructure and the biochemical composition of the fibre wall to explain the experimentally observed behaviour and properties. The difficulties lying with this kind of analysis are directly related to the hierarchical structure of plant fibres, involving a large number of complex mechanisms driven by material and structural characteristics at different scales.

Taking into account the material properties at all scales, as well as the morphology, quickly generates a high calculation cost. From a numerical point of view, solutions exist to overcome the difficulties associated with analyses involving a large number of calculations. One of the most used tools is sensitivity analysis. Primarily designed to identify the most influential parameters in the modelling of a physical system in structural analysis, it also proves to be a powerful tool for understanding and identifying the mechanisms that determine a certain response from the physical system to model [27].

In this paper we propose a numerical study on the relationships between morphological, ultrastructural and material features, along with their variability, and the mechanical properties of flax and hemp fibres, in order to better understand the origins of the observed differences in tensile behaviour between flax and hemp fibres. A previously developed fibre model $[28,29]$ is used to carry out a sensitivity analysis, in order to assess the impact of material, morphological and ultrastructural parameters on the tensile properties and behaviour of flax and hemp elementary fibres.

\section{Methods and materials}

\subsection{D model and behaviour law}

The 3D model used for this study is based on a previously developed formulation. It is fully described in [28] and [20]. It is firstly developed for the study of hemp fibres, but it can be easily adapted to flax, considering they have very similar fibre wall's characteristics. The model is based on macroscopic considerations and uses the continuum mechanics formulation. The original model considers the fibre as a multi-layered cylinder, including all the sub-layers of the fibre wall. In this work, only 
the $S_{2}$ layer is considered, as it represents more than $90 \%$ of the total thickness of the fibre wall, both for hemp and flax fibres [13]. The fibre wall is considered as a long fibre-reinforced composite material in which the fibres are represented by the cellulose microfibrils and the matrix is a mixture of transverse isotropic amorphous cellulose (hemicellulose) and isotropic lignin.

An anisotropic viscoelastic constitutive law is implemented for the material constituting the fibre wall [28]. The elastic properties of the fibre wall (longitudinal and transverse moduli $\mathrm{E}_{\mathrm{L}}, \mathrm{E}_{\mathrm{T}}$, Poisson's ratio $\nu_{\mathrm{LT}}$ and shear modulus $\mathrm{G}_{\mathrm{LT}}$ ) were computed using a multiscale rule of mixture technique and the properties of the main constituents of the cell wall [20].

A spectral formulation $[30,31]$ is used to model the viscoelastic behaviour of the homogenised material of the fibre wall. The viscoelastic strain rates is defined as a superposition of the elementary kinetics $\dot{\xi}_{i}$ :

$$
\underline{\dot{\varepsilon}}^{v e}=\sum_{i=1}^{n} \dot{\dot{\xi}}_{i}=\sum_{i=1}^{n} \frac{1}{\tau_{i}}\left(\mu_{i} \underline{\underline{S}}^{v e} \underline{\sigma}-\underline{\xi}_{i}\right)
$$

Where $\underline{S}^{v e}$ is a fourth order tensor describing the viscous anisotropy. Such a tensor requires, in addition to the classical elastic parameters, the identification of three parameters $\left(\beta_{T}, \beta_{L T}, \beta_{T T}\right)$ related to the viscoelastic behaviour [28]. $\tau_{i}, \mu_{i}$ are obtained from a relaxation times spectrum layout [32]. For this study, a truncated triangle spectrum is used, which is defined by four parameters : $n_{0}, n_{\text {inf }}, n_{\min }, n_{\max }$.

\subsubsection{FE model}

A toolbox previously developed, dedicated to the modelling of the fibre, is used [29]. The coded scripts are able to automatically generate the fibre geometry and mesh and the setting data file for the finite element calculation performed in the FE Abaqus ${ }^{\circledR}$ code. The simulation and postprocessing steps are then automatically carried out (Fig. 1).

The cross-section is kept constant in the fibre length and the morphology is only defined by the degree of ellipticity of the cross-section :

$$
e=1-\frac{b}{a}
$$

where $a$ and $b$ are the largest and the smallest outer diameter of the ellipse. Both outer contour and lumen are elliptical, with the same degree of ellipticity $e$.

As for the study proposed by Del Masto et al. [29], solid 8-nodes-element mesh is used for the finite elements analysis. The length of the modelled fibres is $100 \mu \mathrm{m}$. Tensile test simulations are carried out applying the load through a nodal displacement of both the edges of the fibre, which are kept free to rotate. Dislocations in the fibre wall are neglected, and the MFA, which defines the material direction, is the same in the fibre length and thickness. The modelled geometry also neglects pre-deformation and torsion. The amplitude of the load is chosen in order to obtain an aver- 
age strain rate equal to the usual experimental one, and the global stress-strain curves are obtained as in Trivaudey et al. [28].

\subsection{Sensitivity analysis}

\subsubsection{Input parameters : literature review}

Ranges, mean and standard deviation of morphological and ultrastructural parameters used in this study were determined according to typical values reported in the literature (cf. Table 1).

Three morphological parameters, defining the elliptic section of the fibre, are considered : the fibre diameter $D$, which correspond to twice the $a$ axis in Equation 2, the lumen (i.e. the void in the center of the fibre) diameter $d$ and the degree of ellipticity $e$ defined in Equation 2. Concerning the structure of the $S_{2}$ layer, the parameters selected for the analysis are the initial microfibrils winding angle MFA $(\psi)$, the cellulose mass fraction $m_{c}$ and its crystallinity rate $m_{c r}$.

Table 2 summarizes the ranges of parameters defining the viscoelastic behaviour and elastic properties of the homogenised fibre wall.

Concerning the viscoelasticity, the parameters used in the sensitivity study correspond to those defining the spectrum $\left(n_{0}, n_{\text {inf }}, n_{\min }\right.$ and $\left.n_{\max }\right)$, along with those defining the complaisance matrix $S^{v e}$ used in [28] $\left(\beta_{L T}, \beta_{T T}\right.$ and $\left.\beta_{T}\right)$.

The elastic properties of the homogenised material of the fibre wall are determined from the elastic moduli of all the polymeric constituents of the cell wall, as well as their mass fraction. Due to the lack of experimental data, the values of certain parameters are fixed: this is the case in particular of the proportion hemicellulose/lignin, fixed at $80 / 20 \%$ in the matrix constituting the wall, and densities of the polymers. These parameters will therefore be taken at their nominal values.

\subsubsection{Screening: Morris One At a Time (OAT) method}

The main goal of screening techniques is to identify the subset of non-influent parameters (or factors) in a model, using a reasonable number of calculations. They are particularly suited for the study of large and/or computationally expensive models. The elementary effects' (EE) method [33] is based on an experimental design where factors are increased OAT of a step $\Delta_{i}$ in the inputs domain. $r$ different elementary effects are estimated by randomly sampling $r$ trajectories in the inputs' space. For each trajectory, the computed sensitivity indices are the mean $\mu$ and the standard deviation $\sigma$ of the obtained elementary effects.

The EE method allows a fast computation of sensitivity indices. Nevertheless, it is classified as a qualitative method [34] because it doesn't distinguish the type of probability density function (PDF) of the input parameters, i.e. the meaning of the computed indices cannot be clearly interpreted in terms of variance decomposition. In this study, the Morris screening method is only used to identify 
the most influent factors on the observed outputs. Only these few important parameters are then used to carry out a more time consuming variance based sensitivity analysis.

\subsubsection{Extended Fourier Amplitude Sensitivity Test (EFAST)}

The Fourier Amplitude Sensitivity Test (FAST) [35, 36] allows the computation of the main effects of each input factor to the variance of the output. The multidimensional space of the input parameters (factors) is explored by a suitably defined search-curve. This space-filling curve in the $k_{t h}$ dimensional input space is built so as to explore each factor with a different frequency $\left(\omega_{1}, \omega_{2}, \ldots, \omega_{k},\right)$. The $N$ design points over the curve are selected as follows:

$$
X_{i}\left(s_{j}\right)=G i\left(\sin \omega_{i} s_{j}\right), \quad \forall i=1, \ldots, k, \quad \forall j=1, \ldots, N
$$

where $X_{i}$ is the $i_{t h}$ input factor, the functions $G_{i}$ are chosen according to the desired probability density function of $X_{i}, s_{j}$ is the parametric variable varying in $(-\pi, \pi)$ which is sampled over its range using $N$ points, and $\omega_{i}$ are the frequencies. For this study, an extension of the FAST method is used. Proposed by Saltelli et al. [37], it allows the computation of the total sensitivity indices, which estimate the total effect of factors $X_{i}$, including the $1^{\text {st }}$ order effect and the interaction with the other parameters [38]. An important feature of the Extended FAST is that it's capable of yielding both the main and the total effect indices from the same set of model evaluations, and so it reduces the computational cost of the analysis.

\subsection{Observed outputs}

\subsubsection{Apparent tangent modulus}

Three different observed outputs are used for the sensitivity analysis. The apparent tangent modulus is calculated as the ratio between the increment of the global stress and the increment of the global strain :

$$
E_{a p p}(\varepsilon)=\frac{\Delta \sigma(\varepsilon)}{\Delta \varepsilon}
$$

Since the tensile behaviour of fibres is nonlinear, the apparent tangent modulus is changing during the tensile test, as well as during the simulation. The sensitivity indices are then calculated at each incrementation, i.e. for each value of $E_{a} p p$.

\subsubsection{Failure criterion}

A failure criterion based on the Hashin formulation [39] is used in order to take into account the failure of the fibre. The criterion is applied at the scale of the fibre wall and it allows to distinguish microfibrils from hemicellulose/lignin matrix failure. For tensile behaviour, Hashin's criterion formulation is shown in Equation 5 for microfibrils rupture and in Equation 6 in the case of matrix failure 


$$
\begin{gathered}
\left(\frac{\sigma_{L}}{T_{L}}\right)^{2}+\frac{1}{S_{L T}^{2}}\left(\tau_{L T}^{2}+\tau_{L T^{\prime}}^{2}\right) \leqslant 1 \\
\frac{1}{T_{T}^{2}}\left(\sigma_{T}+\sigma_{T^{\prime}}\right)^{2}+\frac{1}{S_{T T^{\prime}}^{2}}\left(\tau_{T T^{\prime}}^{2}+\sigma_{T} \tau_{T T^{\prime}}\right)+\frac{1}{S_{L T}^{2}}\left(\tau_{L T}^{2}+\tau_{L T^{\prime}}^{2}\right) \leqslant 1
\end{gathered}
$$

The indices $L$ and $T, T^{\prime}$ correspond to the longitudinal and transverse directions of the cellulose microfibrils respectively. Failure occurs when the first of the two thresholds defined by the equations Equation 5 and Equation 6 is reached. The observed output is then the level of global stress at break. This formulation requires the preliminary determination of the terms $T_{L}, T_{T}$ and $S_{L T}, S_{T T^{\prime}}$, which represent the tensile $\left(T_{i i}\right)$ and shear $\left(S_{i j}\right)$ strength respectively, in the directions $i, j=L, T, T^{\prime}$. Given the difficulty of the experimental identification of these terms, the tensile and shear strengths are computed using a rule of mixtures (RoM), starting from those of the constituents of the fibre wall, as shown en Equations 7- 10:

- RoM 1: Microfibrils $(\mathrm{MF})=$ crystalline cellulose $(\mathrm{CC})+$ amorphous cellulose $(\mathrm{AC})$

$$
\begin{gathered}
\sigma_{r_{M F}}=\sigma_{r_{C C}} v_{C C}+\sigma_{r_{A C}}^{\prime}\left(1-v_{C C}\right) \\
\sigma_{r_{A C}}^{\prime}=\varepsilon_{r_{C C}} E_{A C}
\end{gathered}
$$

- RoM 2: Matrix (MAT) = hemicellulose $(\mathrm{HC})+\operatorname{lignin}(\mathrm{LG})$

$$
\sigma_{r_{M A T}}=\sigma_{r_{H C}} v_{H C}+\sigma_{r_{L G}}\left(1-v_{H C}\right)
$$

- RoM 3: Fibre wall $=$ microfibrils $(\mathrm{MF})+\operatorname{matrix}(\mathrm{MAT})$

$$
T_{L}=\sigma_{r_{M F}} v_{M F}+\sigma_{r_{M A T}} v_{M A T}
$$

Equations 7- 10 allows the computation of the tensile strength of the homogenised material of the fibre wall in the direction of the microfibrils from those of the constituents of the wall, namely $\sigma_{r_{C C}}, \sigma_{r_{A C}}, \sigma_{r_{H C}}$ and sigma $_{r_{L G}}$, and their volume fractions. In the literature there is only a very limited number of studies on the identification of the properties of these biological polymers [40, 41, 42, 43]. The strength of the crystalline cellulose is generally comprised between 5 and $10 \mathrm{GPa}$ [42]. In the case of amorphous cellulose, its resistance is calculated via the Equation 9 according to a method conventionally used in the case of unidirectional composites [44].

For the other constituents, however, the lack of experimental data makes it necessary to rely on assumptions.

- Hemicellulose and amorphous cellulose have very similar properties. Therefore, $\sigma_{r_{H C}}=\sigma_{r_{A C}}$. 
- For lignin, its strength is set equal to $\sigma_{r_{H C}} / 2$. This value is justified by the fact that the ratio between the elastic properties of hemicellulose and those of lignin is generally equal to 2 .

The terms $T_{T}, S_{L T}$ and $S_{T T^{\prime}}$ are also obtained by means of hypotheses. Concerning the tensile strength of the fibre in the direction perpendicular to the microfibrils, the ratio of anisotropy of the plant wall $\alpha$ is used, which is defined as the ratio between the Young's modulus of the fibre in the perpendicular and longitudinal directions of the microfibrils. The strength in the perpendicular direction to the fibres is then $T_{T}=\alpha T_{L}$ The difficulty stands, however, when it comes to determining the shear resistances $S_{L T}$ and $S_{T T^{\prime}}$. Again, due to the lack of experimental data, the choice turns to setting these values based on assumptions, taking into account the nature and molecular organisation of the constituents [42]. In particular, we set $S_{L T}=100 \mathrm{MPa}$ and $S_{T T^{\prime}}=50 \mathrm{MPa}$.

\subsubsection{The $\eta$ ratio}

The second observed output is the so-called $\eta$ ratio. It was defined by Lefeuvre et al. [25] as :

$$
\eta=\frac{\sigma_{1}}{\sigma_{1}+\sigma_{2}}
$$

where $\sigma_{1}$ and $\sigma_{2}$ are the global stress at the threshold point of the first nonlinear section of the tensile curve $\left(\varepsilon_{1}, \sigma_{1}\right)$ and at the end of the tensile test respectively (Fig. 2). Lefeuvre et al. suggest that the size of the first nonlinear section, defined by $\varepsilon_{1}$, may indicate the fibre capacity to absorb energy before the reorientation of microfibrils. In a certain way, the $\eta$ ratio may be considered as an indicator of the nonlinearity of the tensile curve, as shown in Fig. 3. For high values of $\eta$, the apparent tangent modulus curve shows a strong inflection in the first loading stage. Inversely, for lower values of the ratio, the apparent tangent modulus is almost constant, expressing a quasi-linear behaviour.

\section{Results and discussions}

\subsection{Screening analysis}

For this work, a total of $k=26$ parameters were involved in the screening analysis. The parameter space is discretised using $p=10$ levels and it is scanned using 15 trajectories. The cost in terms of number of simulations is $n=(k+1) \times r=405$, for both types of fibres. Simulations are carried out using a bi-processor quad-core system with 36 GB of RAM (two days of calculations). The main objective of the screening analysis is the identification of factors that have no, or very little, effect on the global tensile behaviour of the fibre. Once identified, negligible parameters will be set at their nominal values. The observed output is the apparent tangent modulus at each loading level. The results in terms of evolution of sensitivity indices on the mean- standard deviation diagrams of the Elemental Effects (EEs) are shown in Fig. 4a and 4b for flax and hemp fibres respectively. Fig. 4 is 
animated in the electronic version of this paper in order to easily follow the evolution of the indices with respect of the global strain. According to Morris method [33], the most important parameters are those whose indices are the furthest from the origin of the axis in the $\mu(E E s), \sigma(E E s)$ diagram. The results show that, despite the apparent similarity of flax and hemp fibers, the morphological, material and structural parameters do not affect their behaviour in the same way. In the case of flax, three parameters are distinguished themselves from the others whose indices remain close to the origin throughout the simulated tensile: the longitudinal modulus of crystalline cellulose $E_{L_{c c}}$, the initial MFA $\psi$ and the mass fraction of cellulose $m_{c}$ in the wall.

As for hemp fibres, the three parameters $E_{L_{c c}}, \psi$ and $m_{c}$ are also among those having a significant impact on the apparent stiffness. Nevertheless, other important parameters appeared: the crystallinity rate of cellulose $m_{c r}$, along with the viscoelastic spectrum parameter $n_{0}$ and the degree of ellipticity $e$. In addition, the standard deviations of the EES reach values that are almost comparable to those of their means, which indicates a non-negligible role of interactions between parametres [33].

In the electronic version of the paper, Fig. 4 shows the evolution of the Morris indices during the tensile test. This allows us to observe that for both types of fibre the influence of the MFA tends to decrease during the test, i.e. the parameter $\psi$ seems to be more influential at the beginning of loading than at the end of the tensile test. This seems justified by the fact that towards the end of the test, microfibrils are increasingly straightened, which reduces the influence of the angle of winding. The same decrease is obtained for the hemp fibre concerning the parameter $n_{0}$. All other factors, tend to have a higher effect for higher strain level.

These results are partly in agreement with those of a previous work proposed in the literature [20]. In this study the authors used a perfectly circular section fibre model and a purely elastic behaviour to study the relationship between fibre diameter and apparent tangent modulus in the case of hemp. In the cited study, the mass fraction of crystalline cellulose, as well as the longitudinal Young's modulus of crystalline cellulose and the initial MFA, are the parameters which most affect the apparent stiffness. However, in the cited work the mass fraction of cellulose does not seem to remarkably affect the apparent tangent modulus of the fibre. In addition, the $G$ shear modulus of amorphous cellulose, which is not very effective in our study, is one of the most important factors in Placet et al.. The results of the screening step are interesting, but remain qualitative results, in particular because the probability distributions of the input parameters are not taken into account. However, it allows to sort factors according to their importance. Legend in Fig. 4 shows the used parameters ranked in decreasing order of importance. 


\subsection{Variance based sensitivity indices}

\subsubsection{Apparent tangent modulus}

For the variance based sensitivity analysis via the extension of the FAST method, the first seven parameters of the classification resulting from the screening step are considered: the initial angle of the microfibrils $\psi$, the fraction of crystalline cellulose $m_{c r}$, the fraction of cellulose $m_{c}$, the degree of ellipticity $e$, the vicolasticity-related parameter $n_{0}$ and the outer diameter of the fibre $D$. The total number of simulations carried out is 2275 , for both hemp and flax fibres. The analysis for each type of fibre therefore required about two weeks. Normal distribution function are affected to each parameter. The results obtained by observing the apparent tangent modulus are shown in Fig. 5. As for the screening step, the evaluation of the indices at each loading step allows to estimate the evolution of the importance of the parameters during the simulation of the tensile test. The total indices allow to quantify the global effect of a variable on the model's response, whereas the first order indices quantify only the part of variability of the observed output due to the variance of this same variable. A possible difference between these two indices for the same variable proves that the model is sensitive to the interactions of this parameter with the others.

The animated Fig. 5 of the electronic version of the paper shows that from a parameters ranking's point of view, for flax as for hemp fibres, the variable whose effect seems to be predominant throughout the test is the parameter $n_{0}$, which defines the extent of the relaxation spectrum. This result is in contradiction with that of the screening step shown in Fig. 4. The Morris method does not take into account the variance of the parameters, whereas in the FAST method the sensitivity indices are calculated according to the variance of the parameters. Overestimated variance can therefore overestimate the effect of a variable on the model response. Indeed, it is possible that the variance of $n_{0}$ may be overestimated due to errors in the identification method used to assess the viscoelastic parameters, as a consequence of the wide range of observed creep responses [45].

Concerning the other parameters, the animated Fig. 5 shows that it is possible to identify two types of evolution of the indices:

- In the case of flax, the three most important parameters, turn out to be the degree of ellipticity $e$, the mass fraction of crystalline cellulose $m_{c r}$ and the diameter of the fibre $D$. The other parameters follow with very close index values. Concerning the differences between the total and first order indices, results show that they remain limited throughout the test, with the exception of the degree of ellipticity and the mass fraction of crystalline cellulose: the indices relating to these two parameters have indeed a significant difference, corresponding in particular to a level of strain less than $0.7 \%$. This indicates that in the first phase of loading the apparent rigidity is sensitive to the interactions between $m_{c r}$ and $e$. The evolution of the indices is 
expressed, in turn, through a decrease of the two indices in the first phase of the loading (up to a level of strain equal to $0.6-0.7 \%)$, followed by a stabilization which is maintained up to a strain level of $2 \%$ from which all the indices show very large fluctuations;

- Regarding the hemp fibres, the classification of variables is almost identical to that obtained in the case of flax. At the beginning of loading, the only remarkable difference with respect to flax concerns the indices of the fraction of crystalline cellulose and the degree of ellipticity: indeed, the difference between their total indices and the first order is here negligible. Regarding the evolution of the indices, it is similar to that observed for flax up to a strain level of about $1.2 \%$. It is from this global strain value that the impacts of the parameters on the stiffness of the two types of fibres deviate. If in the case of flax the value of the indices tends to stabilize from a certain level of deformation, this plateau is absent in the case of hemp: for $\varepsilon>1.2 \%$ and up to about $2 \%$, the total indices increase rapidly, except for the $e$ parameter. This increase does not concern, or in a very limited way, those of the first order: this implies an amplification of the difference between the two indices and a consequent augmented sensitivity of the stiffness to the interactions between the variables. At the end of the tensile test, the ranking of the parameters changed: for a strain level of about $3 \%$, the most important parameter appears to be the longitudinal modulus of the crystalline cellulose $E_{L_{c c}}$, followed by the $n_{0}$ parameter and the initial MFA $\psi$. The fraction of crystalline cellulose $m_{c r}$, the diameter $D$ and the degree of ellipticity $e$ are, for these levels of deformation, the least effective parameters on the apparent stiffness.

\subsubsection{Strength}

The sensitivity indices obtained by observing the fibre strength are shown in Fig. 6. Once again, the parameter $n_{0}$, one of the viscoelastic parameters, proves to be by far the most influent parameter on the strength for flax and hemp. The remarks made previously about this parameter are valid here as well. Concerning the other parameters, however, a remarkable difference between the two fibres can be observed:

- Crystalline cellulose mass fraction and fibre diameter are the variables that most affect flax fibre strength, with almost identical sensitivity indices. The remaining four parameters follow with very small gaps between their indices. An interesting aspect is the significant difference between the total and first order indices, and this for all the variables: this means that the stress at break of the flax seems to be affected by the interactions between the parameters taken into account.

- In the case of hemp, the only parameter that stands out from the others is the longitudinal 
modulus of crystalline cellulose, the other parameters having low sensitivity indices, both $1^{\text {st }}$ order and total.

These results show for the first time a true difference between these two types of fibres from the point of view of the impact of the parameters on their mechanical properties. This difference proves that, although flax and hemp are two very similar types of fibres, their strength, defined here via a failure criterion, is not influenced in the same way by the material and morphological parameters.

\subsubsection{The $\eta$ ratio}

Regarding the $\eta$ ratio, the interpretation of the results is slightly more delicate. The Fig. 7 shows again a preponderant effect of the parameter $n_{0}$, even if it is weakened compared to the one expressed on the apparent stiffness and the strength. Concerning the remaining parameters, the two types of fibres are characterized by different sensitivity indices:

- The degree of ellipticity and the fraction of cellulose are the most important parameters on the $\eta$ ratio in the case of flax. The $E_{L_{c c}}$ modulus, the fibre diameter and the crystalline cellulose fraction follow the first two, with a negligible difference between their total and $1^{\text {st }}$ order indices. Surprisingly, the MFA is the parameter with the smallest effect on the extent of the non-linear area of the stress-strain curve of flax. In addition, the gap between its indices is very small, indicating that $\eta$ does not seem to be affected by the interactions concerning the MFA. This difference between the total indices and the 1st order is limited, but not negligible for the other parameters.

- The extent of the non-linear area of the hemp fibres behaviour is particularly affected by all the parameters taken into account: the differences between the two types of indices are indeed important for all the parameters. Regarding the ranking, the cellulose fraction is the most influent parameter, closely followed by the MFA and the fibre diameter. The remaining three variables close the ranking with very similar indices.

The most significant difference between the results for the two fibres is probably the MFA related indices. In both cases, the variance of $\psi$ has little effect on the variance of $\eta$. However, its sensitivity to interactions between the MFA and other parameters in the case of hemp makes $\psi$ the second most influential parameter for this type of fibre, while in the case of flax it has a negligible impact on $\eta$.

\subsection{Tensile behaviour, properties and variability}

\subsubsection{Stress-strain behaviour}

Fig. 8 shows the stress-strain curves obtained from the simulations performed for the global sensitivity analysis (2275 curves). 
The stress-strain and apparent tangent modulus-strains curves end at the strain level which corresponds to the the breakage of the fibre, according to the failure criterion used. These envelopes are directly representing all the possible tensile behaviours with respect of the 7 input parameters $\left(E_{L_{c c}}\right.$, $m_{c}, m_{c r}, \psi, D$ and $\left.d\right)$, ranging from nano to micro material scales, along with their variability. By examining the curves obtained with this model-based approach, it is possible to observe three major differences between the two types of modelled fibres:

- The ultimate strain level is generally higher for hemp than for flax, as shown in Fig. 8a and $8 \mathrm{~b}$. This is especially true in the case of fibres with lower initial stiffness, as can be seen in areas of low stress.

- Fig. 8c and Fig. 8d show that from a type of behaviour point of view, flax and hemp fibres show a drop in apparent stiffness from a certain level of strain, which is clearly visible on apparent tangent modulus-strain curves. This response seems to occur more frequently in the case of hemp.

- The variability expressed by the two fibres in apparent rigidity seems comparable, as shown in Fig. 9. Here the evolution of the coefficient of variation is displayed as a function of the overall strain. The coefficient of variation is calculated for each $i$-th level of strain as the ratio of the standard deviation and the mean of the values of the apparent tangent modulus expressed at the $i$-th loading step. The curves end at the mean failure strain calculated for the two types of fibres. This result reveals that flax and hemp fibres express a variability that increases with the level of deformation considered until reaching a coefficient of variation of about 0.48 . This maximum is reached at a strain level equal to $0.6 \%$ for hemp and about $1 \%$ for flax. Once the maximum reached, in the case of hemp the variability decreases until the mean strain at failure, while for flax the coefficient of variation remains constant.

\subsubsection{Tensile properties}

The Table 2 shows a comparison between the mechanical properties of flax and hemp fibre resulting from experimental works published in the literature and those obtained by simulation during this work. Results obtained in terms of initial stiffness are consistent with the data of the literature. On the other hand, large deviations are observed with respect to the strength and the strain at break, as well as to the $\eta$ ratio. In this work the failure is supposed to occur when the stress level in a finite element of the model satisfies the Hashin criterion defined in Equation 5 and 6. In this numerical study, failure occurs for lower strain values compared to the experimental case. It follows from the Equation 11 that the $\eta$ Equation 5 is partly overestimated. These differences between the properties experimentally measured and those obtained numerically can be due to several factors: 
- in this work the break is supposed to occur as soon as the implemented criterion is exceeded : indeed, the proposed approach does not take into account the progressive failure, due to the viscoelastic behaviour of the constituents of the fibre wall. Also, the criterion is based on the application of the rule of of mixture to compute the tensile and shear strength of the fibre wall. This implies that the bonding between microfibrils and matrix within the fibre wall is assumed to be perfect, which is not the case in reality since stick-slip mechanisms may occur. This criterion may prove to be poorly adapted and result in an underestimation of the strength;

- the ultimate strain can be overestimated experimentally, since it is usually calculated from the displacement of the test machine. Indeed, Fuentes et al. [46] showed, using a digital image correlation (DIC) method, that the overall strain calculated from the displacement is overestimated with respect to the deformation average obtained by DIC. In the future, it is recommended to compare numerical computed tensile behaviour and properties with those obtained experimentally through digital image correlation techniques in order to correctly estimate the goodness of numerical models for this kind of fibres.

Concerning the variability of the properties, the scattering observed experimentally on the initial stiffness is close to the one obtained numerically, and this for the two types of fibres analysed (cf. Table 3). In the case of strength and strain at break, the standard deviations obtained in this study are close to the experimental ones for hemp fibres. In the case of flax fibres, on the other hand, the variability of the strength and strain at failure resulting from the simulations are lower than the experimental ones.

From the simulations, it is possible to investigate the existence of relationships between the properties estimated numerically. The Fig. 10 shows the results in terms of strength versus initial apparent tangent modulus for flax and hemp. There is a direct relationship of proportionality between apparent stiffness and fibre and its strength. This relation, observed experimentally for different species of fibres in several studies of the literature [17, 24, 18, 47], is confirmed by a coefficient of determination $r^{2}$ equal to 0.673 for flax and 0.65 for hemp. Lefeuvre et al. [25] show that there is also an inverse relationship between the extent of the nonlinear zone of the stress-strain curve, estimated by the $\eta$ ratio, and the mechanical properties of fibres.

The Fig. 11 show the relationship between strength and $\eta$ ratio for flax (Fig. 11a) and hemp (Fig. 11b). Power functions, whose parameters are summarized in Table 4, are superimposed on the results obtained. It is possible to note that the observations of Lefeuvre et al. here are confirmed: either for flax or hemp, high values of eta ratio lead to a deterioration of fibre strength.

Another relation conventionally identified in the experimental studies is the one between the fibre 
diameter and the strength $[17,24,12,48,19]$. An inverse relation is observed between the diameter of the fibres and their resistance. This is supposed to be a direct consequence of the greater probability of occurrence of defects when the dimensions of the fibre increase [49]. Fig. 12a and 12b shows the obtained strength and initial stiffness values respectively as a function of the diameters of the modelled flax and hemp fibres.

It is clear that no relationship between diameter and strength is here observable: indeed, in this study, the possible presence of defects in the fibre wall is neglected. The same conclusions stands regarding the relationship between diameter and stiffness. In this case also, several authors have observed an inverse relation between the diameter and the stiffness of the fibres [47, 18] whose physical

origin is more difficult to understand. However, the results of the simulations show here that the apparent stiffness of the fibre is not correlated to its diameter.

\subsection{Discussion}

Fig. 13 shows the results in terms of probability density functions of the initial apparent tangent modulus $E_{0}$ for flax and hemp fibres. 300 simulations are carried out using different values of standard deviation for two input parameters: the fibre diameter $D$ and the mass fraction of crystalline cellulose $m_{c r}$. Means and standard deviations of the normal distributions affected to these parameters are summarised in Table 5. All the other parameters are kept to their nominal values (cf. Table 1 and Table 2).

As shown in Fig. 13, a diminution of the variability of $D$ and $m_{c r}$ leads to an increase of about $7 \%$ of the average initial apparent stiffness of hemp fibres (cf. Table 5). In other words, the observed differences in average mechanical properties for flax and hemp fibres seem to be directly related to the variability of some morphological, ultrastructural and fibre wall material parameters. In particular, the lower average of apparent stiffness generally observed for hemp fibres can be explained by the higher variability of fibre diameter and mass fraction of crystralline cellulose.

\section{Conclusions}

In this paper, a comparative study on the relationships between morphology, ultrastructure and fibre wall material and the tensile behaviour and properties of flax and hemp fibres is proposed through a numerical approach. The effect on the expressed tensile behaviour of the variability of the multiscale parameters characterising the morphology, the ultrastructure and the material of the fibres is assessed through a two-steps sensitivity analysis. Results in terms of sensitivity indices showed that the parameters taken into account do not have the same influence on the observed outputs for the two types of fibres. 
Results of the numerical study proposed in this paper also show that the difference observed in average mechanical properties of flax and hemp fibres are partly due to the differences in scattering of some morphological, ultrastructural and fibre wall material parameters. Indeed, for some parameters, variability reported in the literature in the case of hemp is twice the one observed for flax. This leads to lower values of average mechanical properties, like the initial apparent stiffness. Simulations show that a diminution of the standard deviation of the fibre diameter and the mass fraction of crystalline cellulose leads to an increase of about $7 \%$ of the initial apparent stiffness in the case of hemp fibres.

\section{Aknowledgements}

The authors would like to aknowledge the French Ministry of Higher Education and Research for the financial support granted to the $\mathrm{PhD}$ program during which the present work was carried out.

\section{References}

[1] A. K. Mohanty, S. Vivekanandhan, J.-M. Pin, M. Misra, Composites from renewable and sustainable resources: Challenges and innovations, Science (80-. ). 362 (2018) 536-542.

[2] M. Ramesh, K. Palanikumar, K. H. Reddy, Plant fibre based bio-composites: Sustainable and renewable green materials, Renew. Sustain. Energy Rev. 79 (2017) 558-584.

[3] T. Gurunathan, S. Mohanty, S. K. Nayak, A review of the recent developments in biocomposites based on natural fibres and their application perspectives, 2015.

[4] A. Bledzki, Composites reinforced with cellulose based fibres, Prog. Polym. Sci. 24 (1999) 221274 .

[5] O. Faruk, A. K. Bledzki, H.-P. Fink, M. Sain, Biocomposites reinforced with natural fibers: 2000 - 2010, Prog. Polym. Sci. 37 (2012) 1552-1596.

[6] A. Bourmaud, J. Beaugrand, D. U. Shah, V. Placet, C. Baley, Towards the design of highperformance plant fibre composites, Prog. Mater. Sci. 97 (2018) 347-408.

[7] L. Bonnétat, Les plantes textiles : lin, chanvre, etc., Hachette, 1907.

[8] J. Müssig, C. Stevens, Industrial Applications of Natural Fibres: Structure, Properties and Technical Applications, John Wiley \& Sons, 2010.

[9] A. Lefeuvre, A. Bourmaud, C. Morvan, C. Baley, Tensile properties of elementary fibres of flax and glass: Analysis of reproducibility and scattering, Mater. Lett. 130 (2014) 289-291. 
[10] L. Marrot, A. Lefeuvre, B. Pontoire, A. Bourmaud, C. Baley, Analysis of the hemp fiber mechanical properties and their scattering (Fedora 17), Ind. Crops Prod. 51 (2013) 317-327.

[11] C. Bergfjord, B. Holst, A procedure for identifying textile bast fibres using microscopy: Flax, nettle/ramie, hemp and jute, Ultramicroscopy 110 (2010) 1192-1197.

[12] K. Charlet, J. P. Jernot, J. Breard, M. Gomina, Scattering of morphological and mechanical properties of flax fibres, Ind. Crops Prod. 32 (2010) 220-224.

[13] A. R. Bunsell, Handbook of Tensile Properties of Textile and Technical Fibres, 2009.

[14] L. G. Thygesen, Quantification of dislocations in hemp fibers using acid hydrolysis and fiber segment length distributions (2007).

[15] A. Bourmaud, J. Malvestio, N. Lenoir, D. Siniscalco, A. Habrant, A. King, D. Legland, C. Baley, J. Beaugrand, Exploring the mechanical performance and in-planta architecture of secondary hemp fibres, Ind. Crops Prod. 108 (2017) 1-5.

[16] C. Goudenhooft, D. Siniscalco, O. Arnould, O. Sire, T. G. Id, C. Baley, Investigation of the Mechanical Properties of Flax Cell Walls during Plant Development : The Relation between Performance and Cell Wall Structure, Fibers 6 (2018) 1-9.

[17] L. Marrot, A. Bourmaud, P. Bono, C. Baley, Multi-scale study of the adhesion between flax fibers and biobased thermoset matrices, Mater. Des. 62 (2014) 47-56.

[18] K. Charlet, Contribution à l'étude de composites unidirectionnels renforcés par des fibres de lin : relation entre la microstructure de la fibre et ses propriétés mécaniques (2008) 184.

[19] C. Baley, Analysis of the flax fibres tensile behaviour and analysis of the tensile stiffness increase, Compos. - Part A Appl. Sci. Manuf. 33 (2002) 939-948.

[20] V. Placet, F. Trivaudey, O. Cisse, V. Gucheret-Retel, M. L. Boubakar, Diameter dependence of the apparent tensile modulus of hemp fibres: A morphological, structural or ultrastructural effect?, Compos. Part A Appl. Sci. Manuf. 43 (2012) 275-287.

[21] J. Müssig, S. Amaducci, Scanner based image analysis to characterise the influence of agronomic factors on hemp (Cannabis sativa L.) fibre width, Ind. Crops Prod. 113 (2018) 28-37.

[22] L. T. Mohanty, A. K., Misra, M., and Drzal, Natural fiber, Biopolymer, and Biocomposites., CRC Press, Taylor \& Francis, 2005.

[23] A. Bergander, L. Salmén, Cell wall properties and their effects on the mechanical properties of fibers, J. Mater. Sci. 37 (2002) 151-156. 
[24] A. Duval, A. Bourmaud, L. Augier, C. Baley, Influence of the sampling area of the stem on the mechanical properties of hemp fibers, Mater. Lett. 65 (2011) 797-800.

[25] A. Lefeuvre, A. Bourmaud, C. Morvan, C. Baley, Elementary flax fibre tensile properties: Correlation between stressstrain behaviour and fibre composition, Ind. Crops Prod. 52 (2014) 762769.

[26] A. Thuault, J. Bazin, S. Eve, J. Bréard, M. Gomina, Numerical study of the influence of structural and mechanical parameters on the tensile mechanical behaviour of flax fibres, J. Ind. Text. 44 (2014) 22-39.

[27] A. Saltelli, S. Tarantola, F. Campolongo, Sensitivity Anaysis as an Ingredient of Modeling, Stat. Sci. 15 (2000) 377-395.

[28] F. Trivaudey, V. Placet, V. Guicheret-Retel, M. L. Boubakar, Nonlinear tensile behaviour of elementary hemp fibres. Part II: Modelling using an anisotropic viscoelastic constitutive law in a material rotating frame, Compos. Part A Appl. Sci. Manuf. 68 (2015) 346-355.

[29] A. Del Masto, F. Trivaudey, V. Guicheret-Retel, V. Placet, L. Boubakar, Nonlinear tensile behaviour of elementary hemp fibres: a numerical investigation of the relationships between 3D geometry and tensile behaviour, J. Mater. Sci. 52 (2017) 6591-6610.

[30] F. Richard, D. Perreux, The safety-factor calibration of laminates for long-term applications: Behavior model and reliability method, Compos. Sci. Technol. 61 (2001) 2087-2094.

[31] M. L. Boubakar, L. Vang, F. Trivaudey, D. Perreux, A meso-macro finite element modelling of laminate structures Part II: Time-dependent behaviour, Compos. Struct. 60 (2003) 275-305.

[32] J.-F. Maire, Etudes théorique et expérimentale du comportement de matériaux composites en contraintes planes, Ph.D. thesis, Université de Franche-Comté, 1992.

[33] M. D. Morris, Factorial Sampling Plans for Preliminary Copmputational Experiments, Technometrics 33 (1991) 161-174.

[34] F. Campolongo, A. Saltelli, J. Cariboni, From screening to quantitative sensitivity analysis. A unified approach, Comput. Phys. Commun. 182 (2011) 978-988.

[35] R. I. Cukier, C. M. Fortuin, K. E. Shuler, A. G. Petschek, J. H. Schaibly, Study of the sensitivity of coupled reaction systems to uncertainties in rate coefficients. I Theory, J. Chem. Phys. 59 (1973) 3873-3878. 
[36] R. I. Cukier, J. H. Schaibly, K. E. Shuler, Study of the sensitivity of coupled reaction systems to uncertainties in rate coefficients. III. Analysis of the approximations, J. Chem. Phys. 63 (1975) 1140-1149.

[37] A. Saltelli, S. Tarantola, K. Chan, A Quantitative Model-Independent Method for Global Sensitivity Analysis of Model Output, Technometrics 41 (1999) 39-56.

[38] I. Sobol, Sensitivity estimates for non linear mathematical models, Math. Model. Comput. Exp. 1 (1993) 407-414.

[39] Z. Hashin, Failure Criteria for Unidirectional Fiber Composites, J. Appl. Mech. 47 (1980) 329.

[40] I. Sakurada, K. Kaji, K. Nakamae, S. Wadano, Experimental Determination of the Elastic Moduli of Polymer Crystals in the Direction Perpendicular to the Chain Axis, Bull. Institue Chem. Res. Kyoto Univ. 44 (1966) 168-182.

[41] A. Ishikawa, T. Okano, J. Sugiyama, Fine structure and tensile properties of ramie fibres in the crystalline form of cellulose I, II, III and IV, Polymer (Guildf). 38 (1997) 463-468.

[42] A. Dufresne, Cellulose and potential reinforcement, in: Nanocellulose. From Nat. to High Perform. Tailored Mater., c, 2012, pp. 1-42.

[43] K. Kulasinski, S. Keten, S. V. Churakov, R. Guyer, J. Carmeliet, D. Derome, Molecular mechanism of moisture-induced transition in amorphous cellulose, ACS Macro Lett. 3 (2014) 10371040.

[44] J. N. Reddy, Mechanics of Composite Materials and Structures, 361 ed., NATO Science Series, 1999.

[45] O. Cisse, V. Placet, V. Guicheret-Retel, F. Trivaudey, M. L. Boubakar, Creep behaviour of single hemp fibres. Part I: viscoelastic properties and their scattering under constant climate, J. Mater. Sci. 50 (2015) 1996-2006.

[46] C. A. Fuentes, P. Willekens, J. Petit, C. Thouminot, J. Müssig, L. M. Trindade, A. W. Van Vuure, Effect of the middle lamella biochemical composition on the non-linear behaviour of technical fibres of hemp under tensile loading using strain mapping, Compos. Part A Appl. Sci. Manuf. 101 (2017) 529-542.

[47] E. Bodros, C. Baley, Study of the tensile properties of stinging nettle fibres (Urtica dioica), Mater. Lett. 62 (2008) 2147-2149. 
[48] M. Fan, Characterization and performance of elementary hemp fibers: factors influenceing tensile strength, Bioresources 5 (2010) 2307 - 2322.

[49] W. Weibull, A Statistical Theory of the Strength of Materials, 1939.

[50] S. A. Grishanov, R. J. Harwood, I. Booth, A method of estimating the single flax fibre fineness using data from the LaserScan system, Ind. Crops Prod. 23 (2006) 273-287.

[51] C. Mattrand, A. Béakou, K. Charlet, Numerical modeling of the flax fiber morphology variability, Compos. Part A Appl. Sci. Manuf. 63 (2014) 10-20.

[52] D. Crônier, B. Monties, B. Chabbert, Structure and chemical composition of bast fibers isolated from developing hemp stem, J. Agric. Food Chem. 53 (2005) 8279-8289.

[53] T. Schäfer, B. Honermeier, Effect of sowing date and plant density on the cell morphology of hemp (Cannabis sativa L.), Ind. Crops Prod. 23 (2006) 88-98.

[54] L. G. Thygesen, M. Eder, I. Burgert, Dislocations in single hemp fibres-investigations into the relationship of structural distortions and tensile properties at the cell wall level, J. Mater. Sci. $42(2007) 558-564$.

[55] J. W. Hearle, The fine structure of fibers and crystalline polymers. III. Interpretation of the mechanical properties of fibers, J. Appl. Polym. Sci. 7 (1963) 1207-1223.

[56] H. H. Wang, J. G. Drummond, S. M. Reath, K. Hunt, P. A. Watson, An improved fibril angle measurement method for wood fibres, Wood Sci. Technol. 34 (2001) 493-503.

[57] C. Baley, Fibres naturelles de renfort pour matériaux composites, Tech. l'ingénieur Surfaces Struct. Fonct. base docum (2005).

[58] V. Placet, A. Bouali, P. Perré, The possible role of microfibril angle of Hemp fibre during fatigue tests and its determination using Wide-Angle X-ray diffraction, Matériaux Tech. 99 (2011) $683-689$.

[59] O. Cisse, Caractérisation du comportement hygro-mécanique des fibres liberiennes élémentaires issues du chanvre, Ph.D. thesis, Université de Franche-Comté, Besançon, 2014.

[60] I. Diddens, B. Murphy, M. Krisch, M. Mu, Anisotropic Elastic Properties of Cellulose Measured Using Inelastic X-ray Scattering, Macromolecules 41 (2008) 9755-9759.

[61] F. L. Dri, L. G. Hector, R. J. Moon, P. D. Zavattieri, Anisotropy of the elastic properties of crystalline cellulose I $\beta$ from first principles density functional theory with Van der Waals interactions, Cellulose 20 (2013) 2703-2718. 


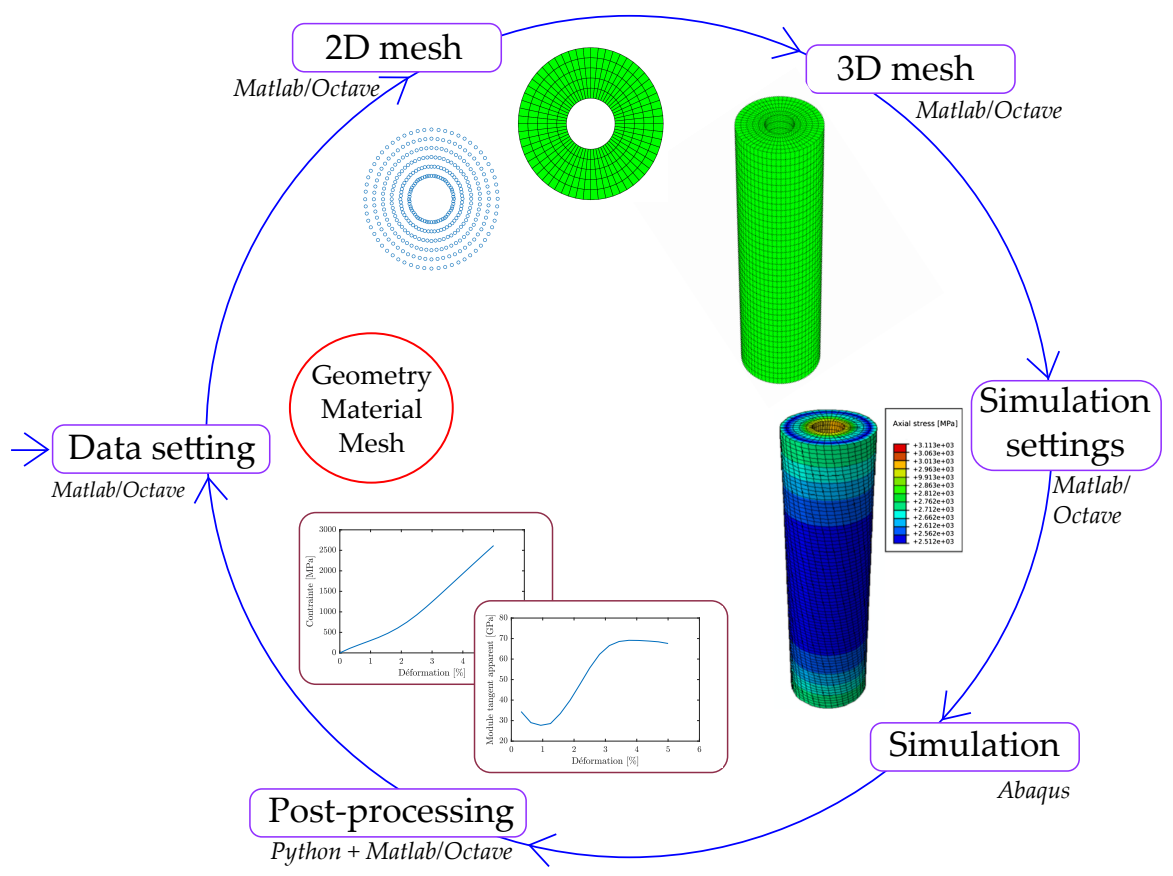

Fig. 1: Schematic representation of the automated process of FE model generation, simulation and post-processing.
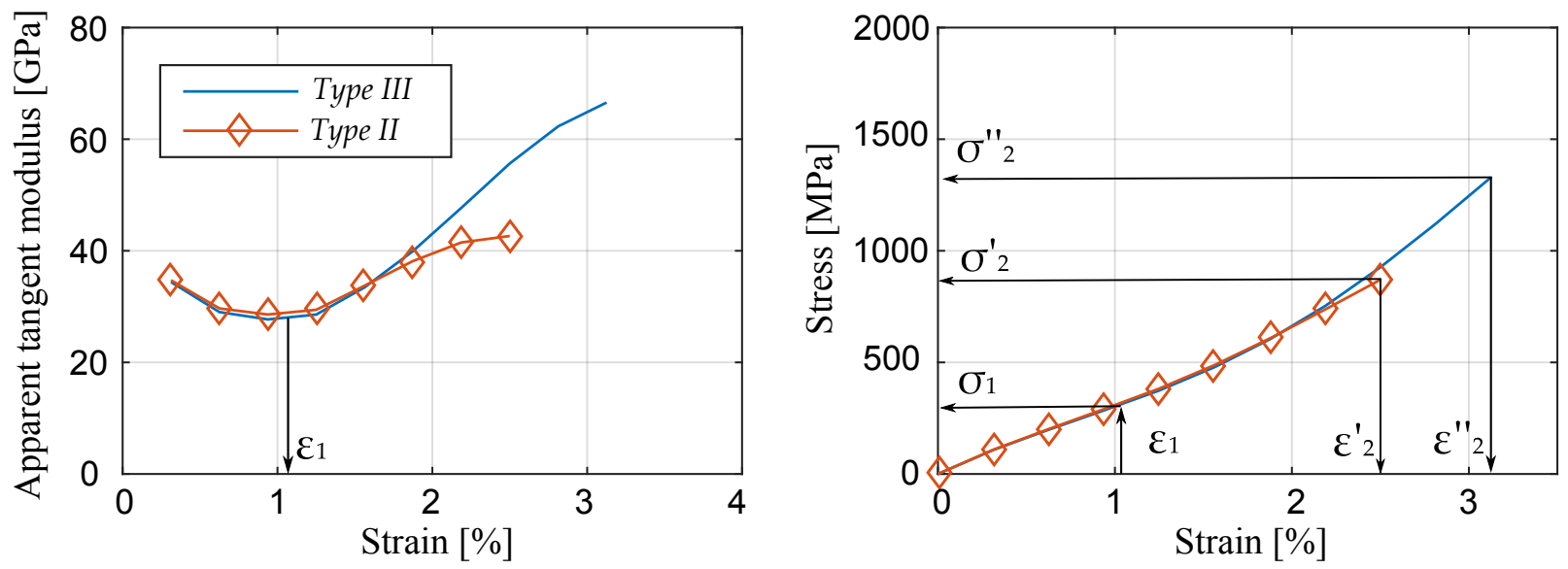

Fig. 2: Representation of stress thresholds $\sigma 1$ and $\sigma_{2}$ on a stress strain curve. 

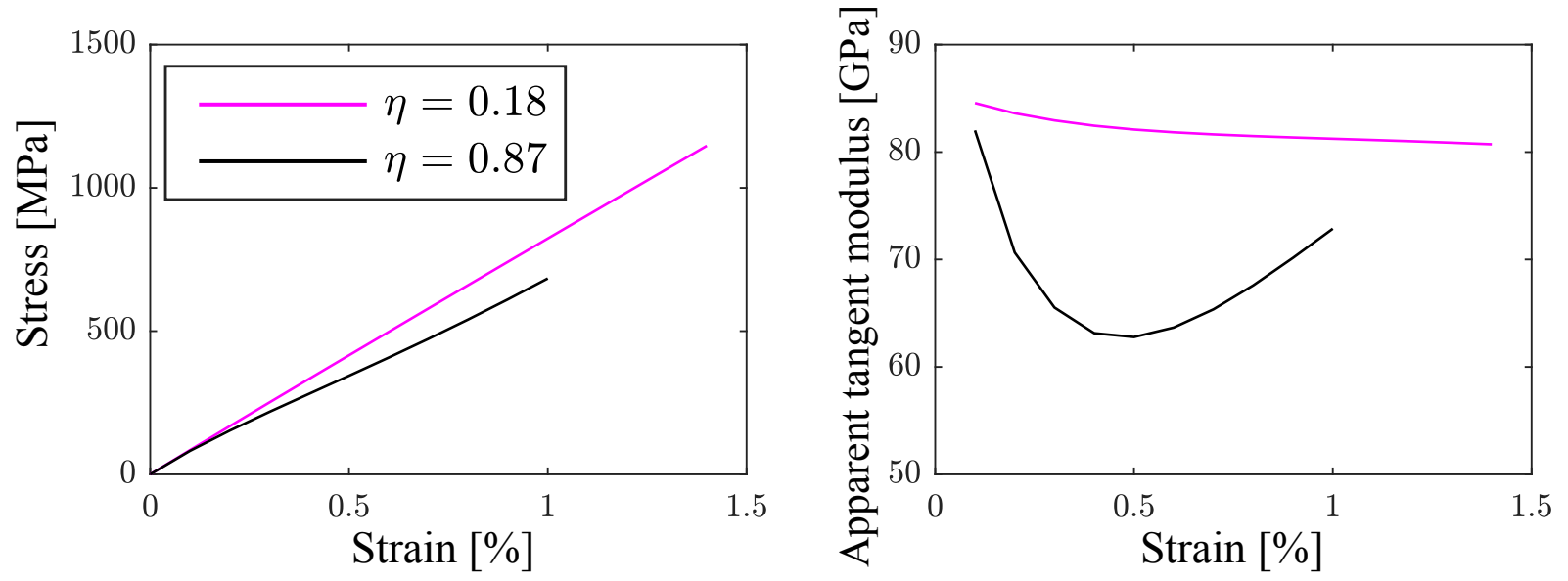

Fig. 3: Behaviours obtained for extreme values of $\eta$ ratio. 


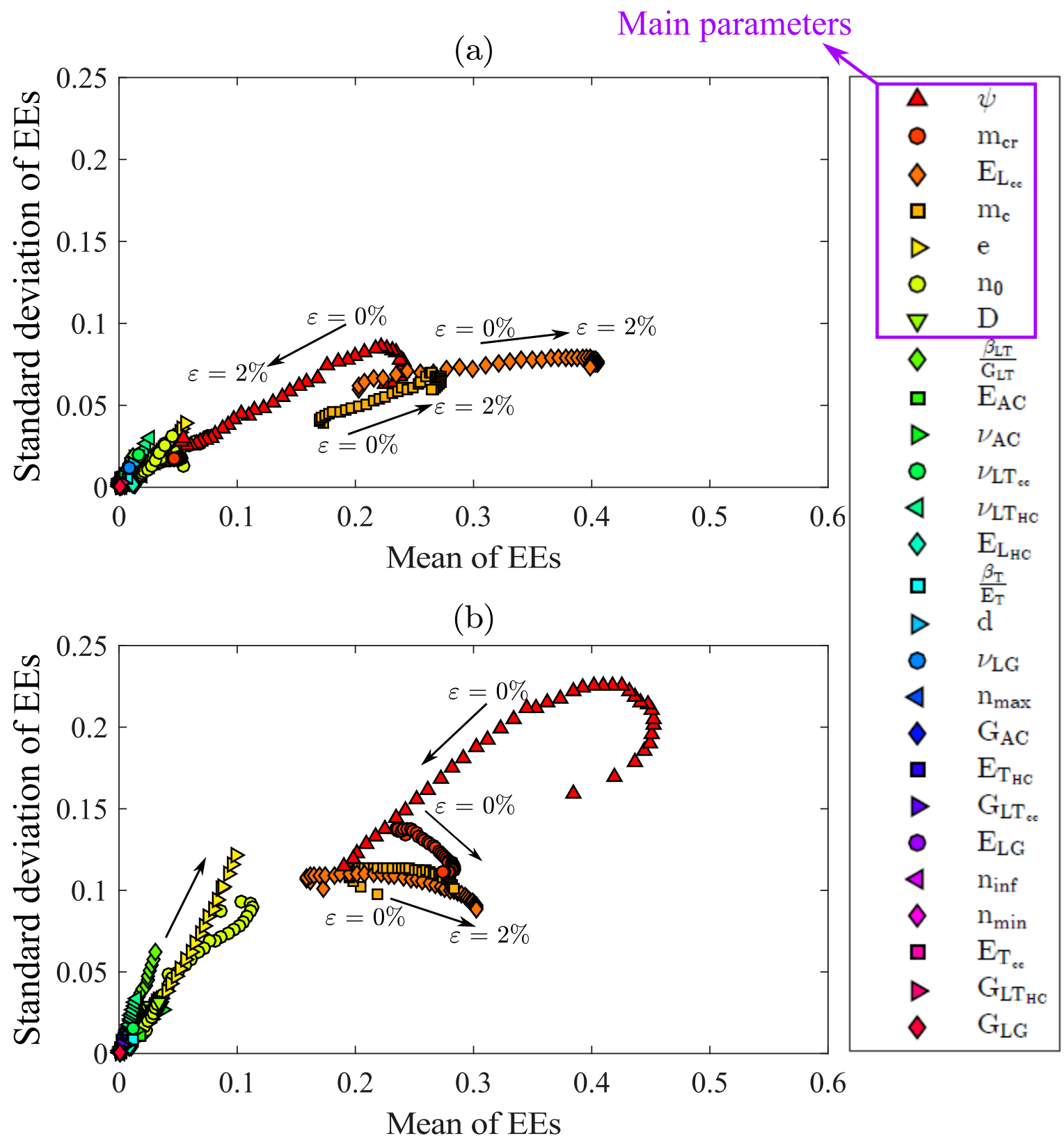

Fig. 4: Video1 should be placed hereEvolution of Morris sensitivity indices with respect to the global strain of the fibre for flax (a) and hemp (b). Parameters in the legend are listed in order of importance. Observed output: apparent tangent modulus. 

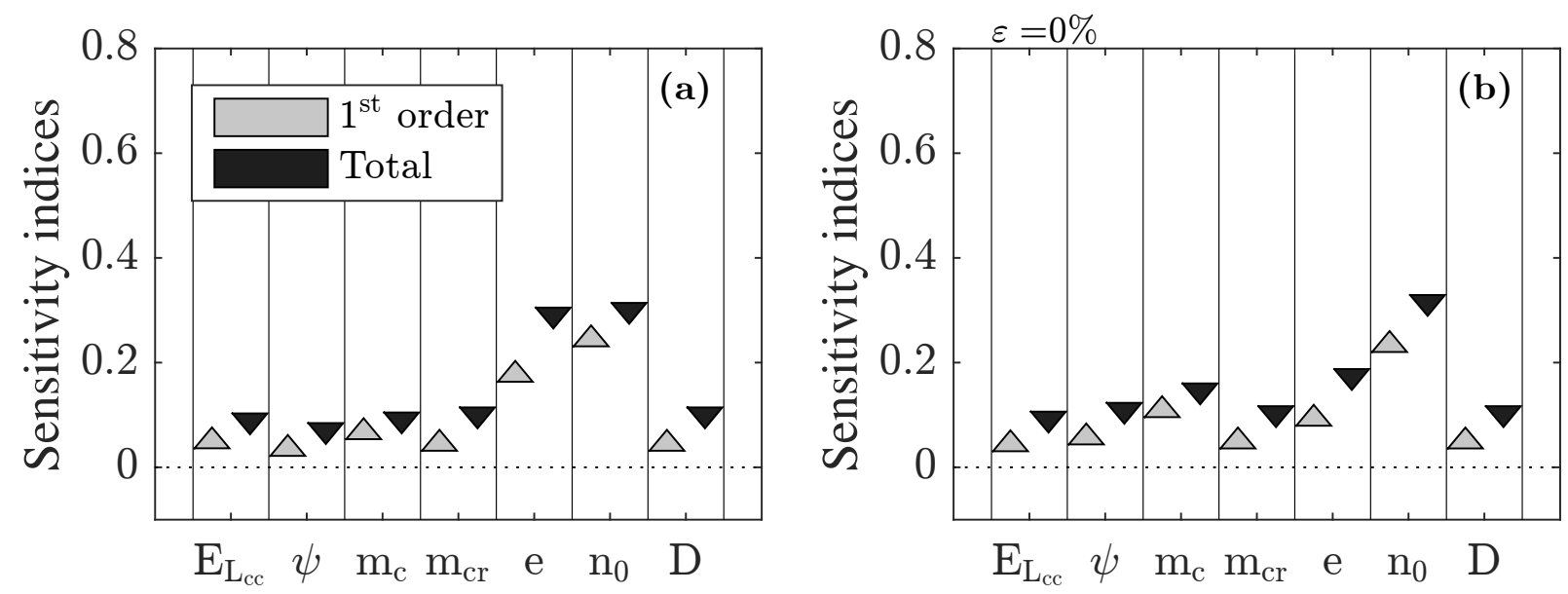

Fig. 5: Video2 should be placed here Evolution of first order and total sensitivity indices with respect to the global strain of the fibre for flax (a) and hemp (b). Observed output: apparent tangent modulus.
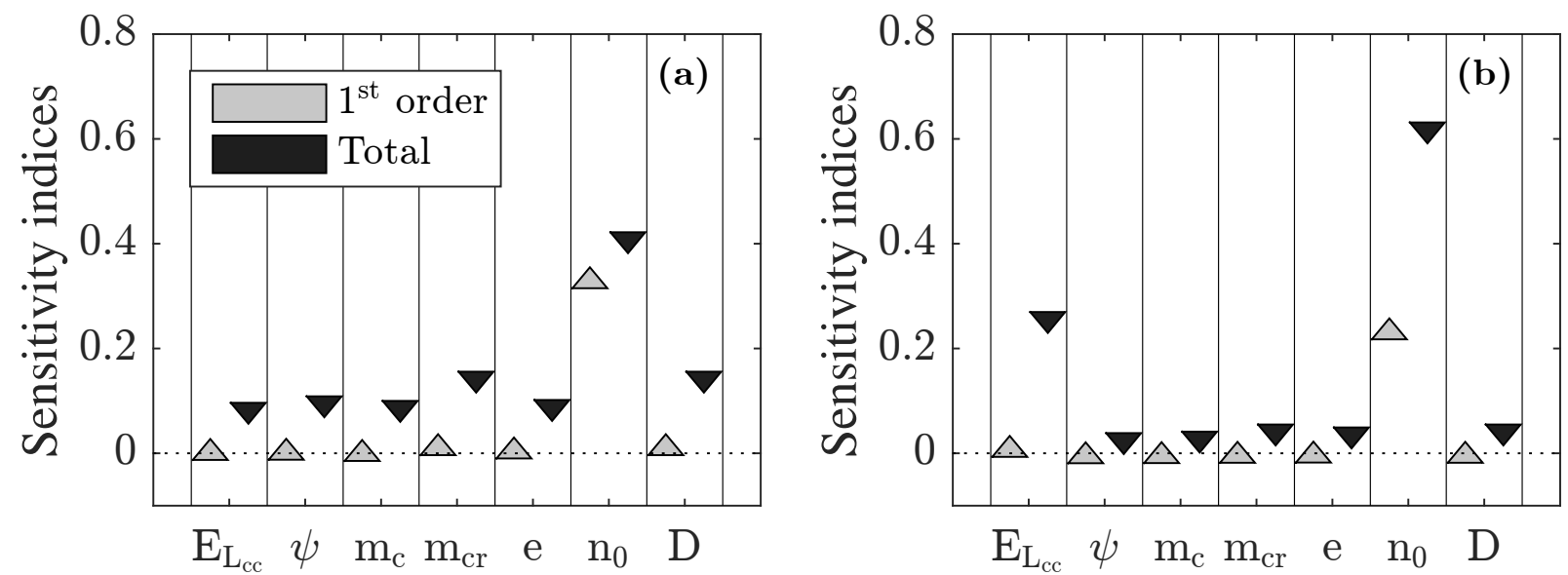

Fig. 6: $1^{\text {st }}$ order and total sensitivity indices for flax (a) and hemp (b) fibre. Observed output: strength. 

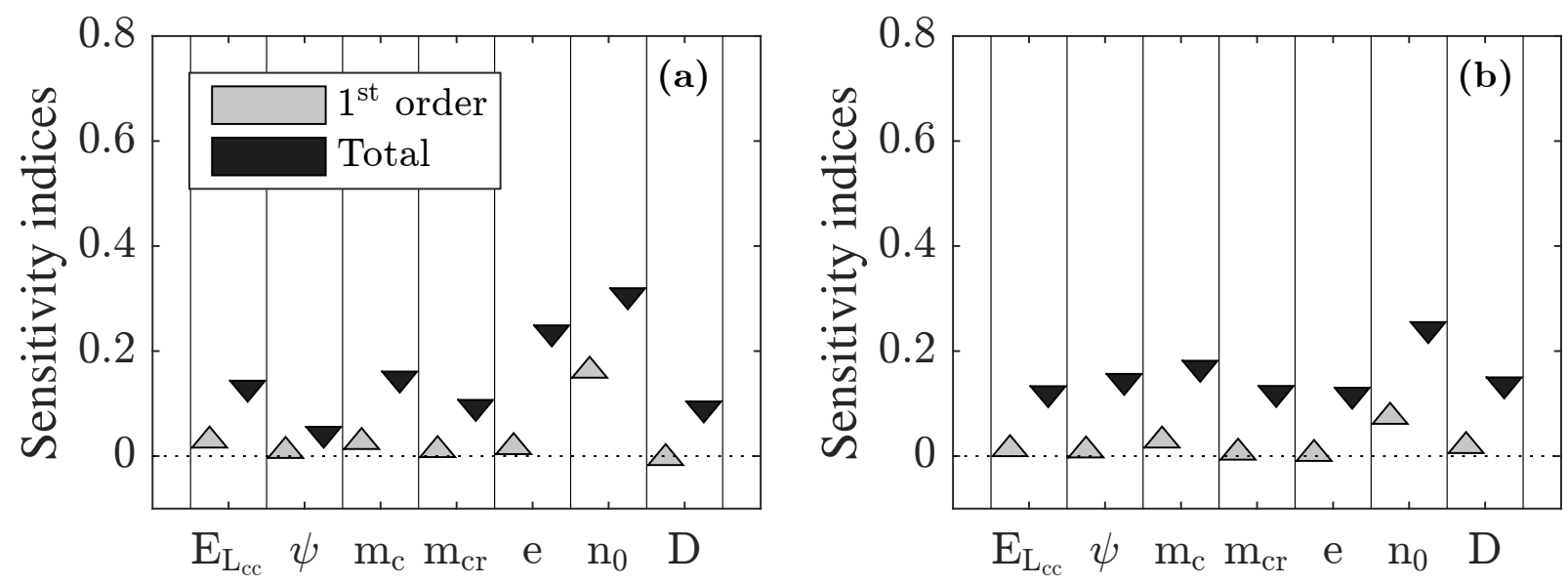

Fig. 7: $1^{\text {st }}$ order and total sensitivity indices for flax (a) and hemp (b) fibre. Observed output: $\eta$ ratio.
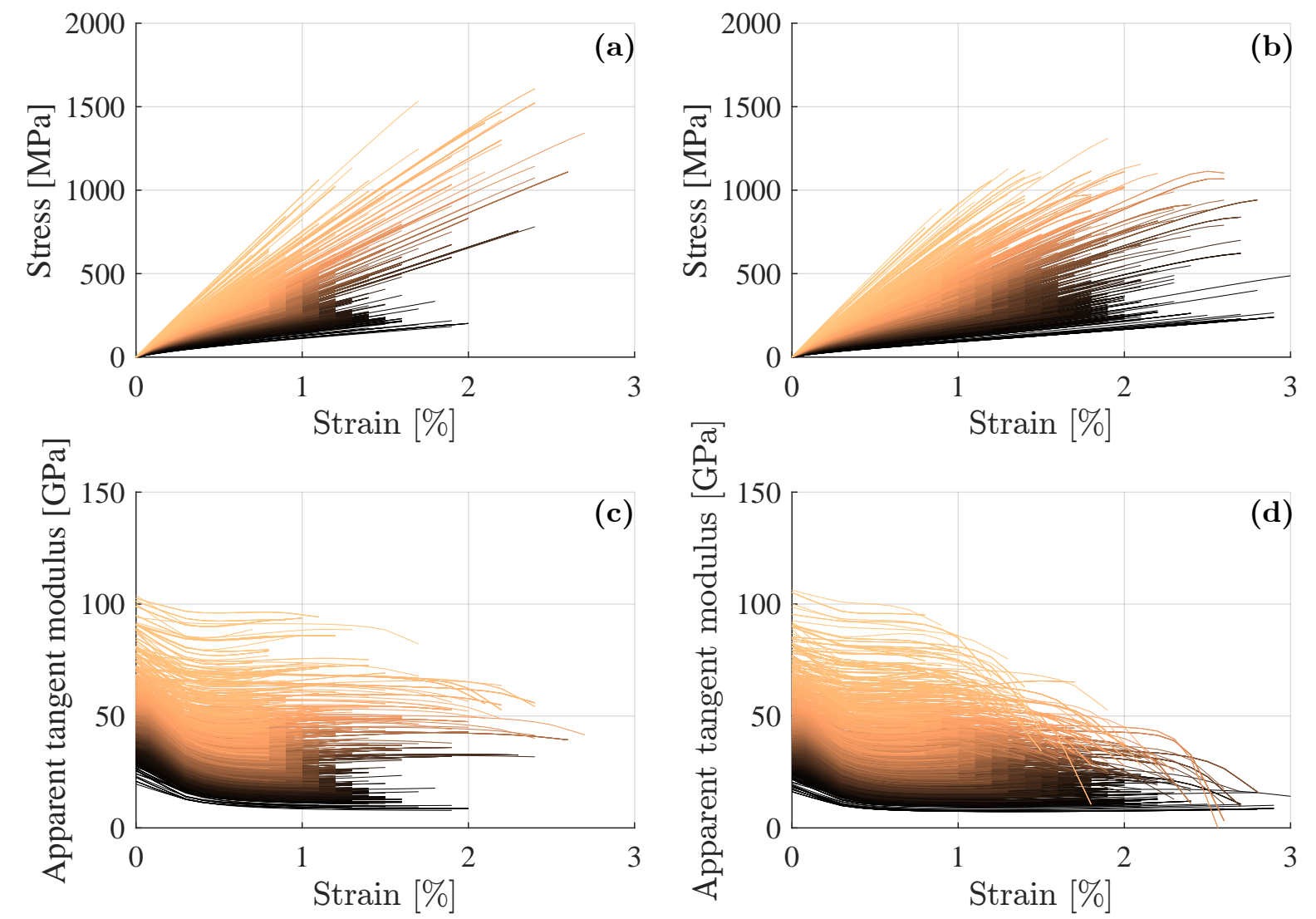

Fig. 8: Comparison between tensile behaviours obtained for flax and hemp fibres. Stress-strain curves (a and b) and apparent tangent modulus-strain curves (c and d) obtained for flax (a and c) and hemp (b and d). 


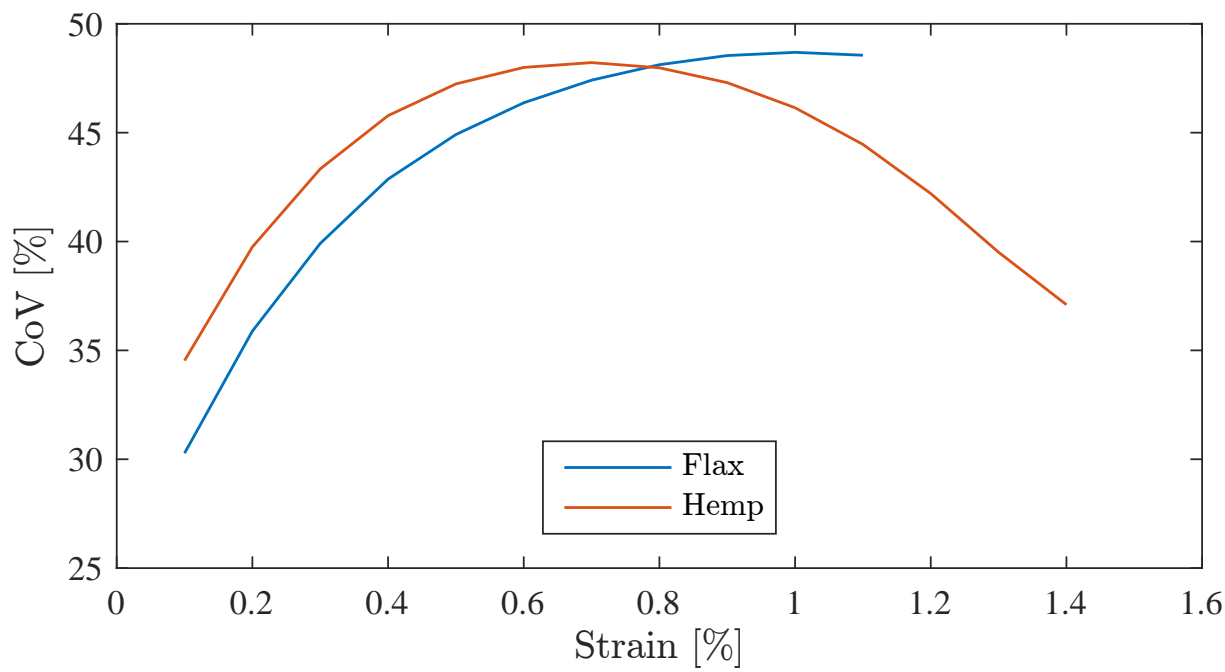

Fig. 9: Evolution of the coefficient of variation $(\mathrm{CoV})$ of the apparent tangent modulus for flax and hemp plotted as a function of the strain.
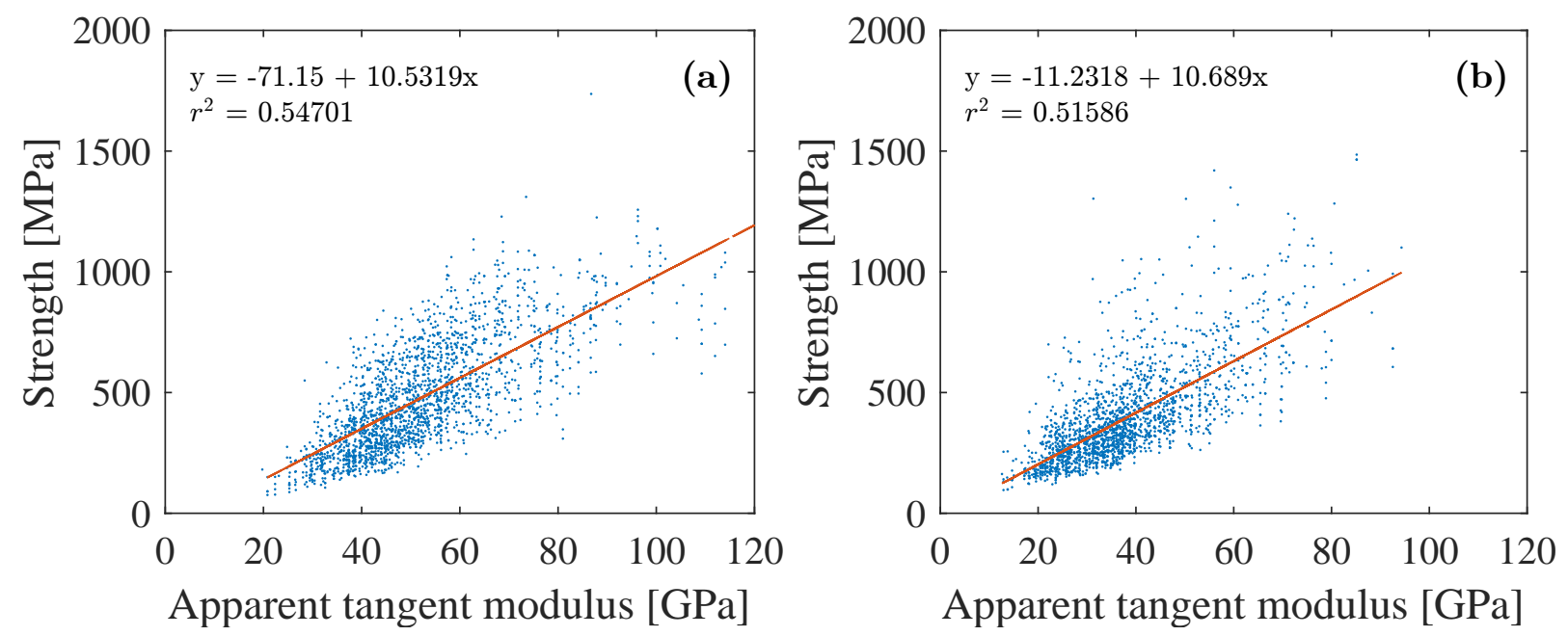

Fig. 10: Relationship between initial apparent tangent modulus and strength for flax (a) and hemp (b) fibres. 

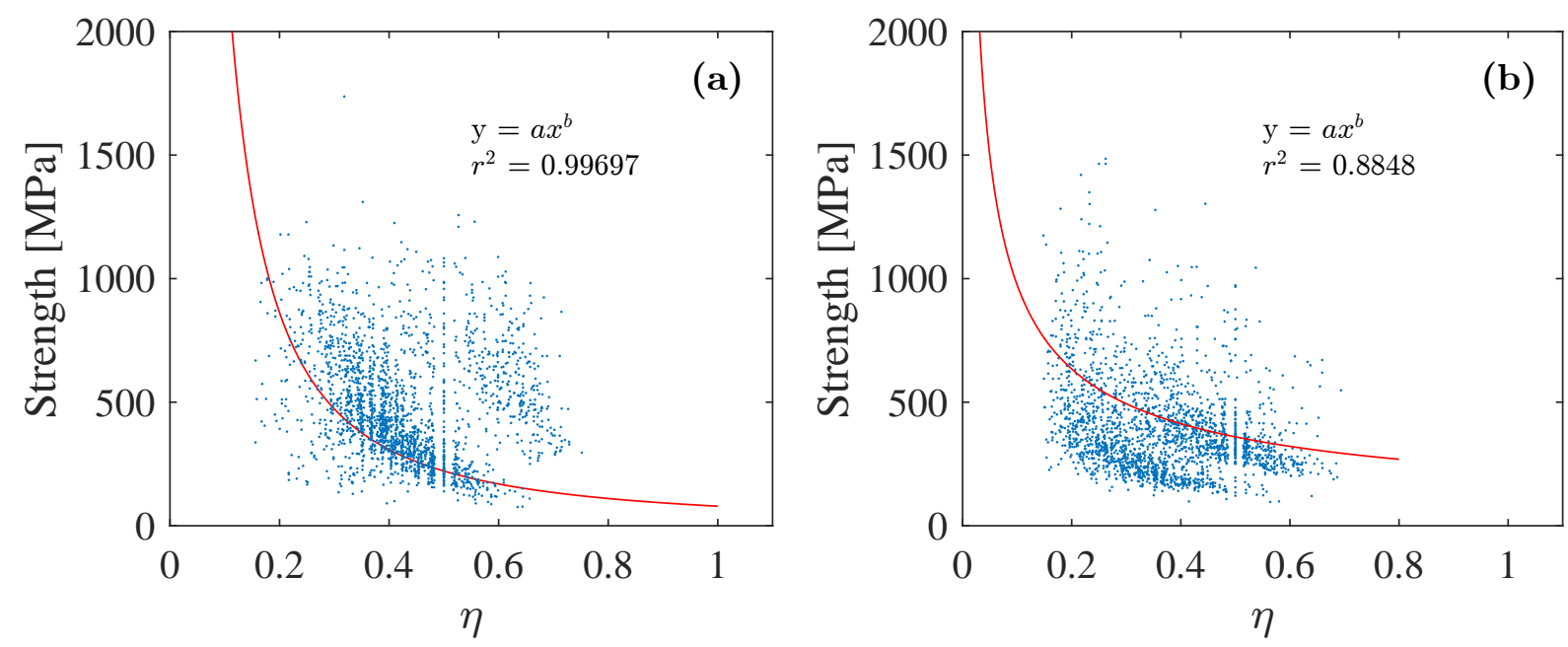

Fig. 11: Relationship between the $\eta$ ratio and the strength for flax (a) and hemp (b) fibres.

(a)

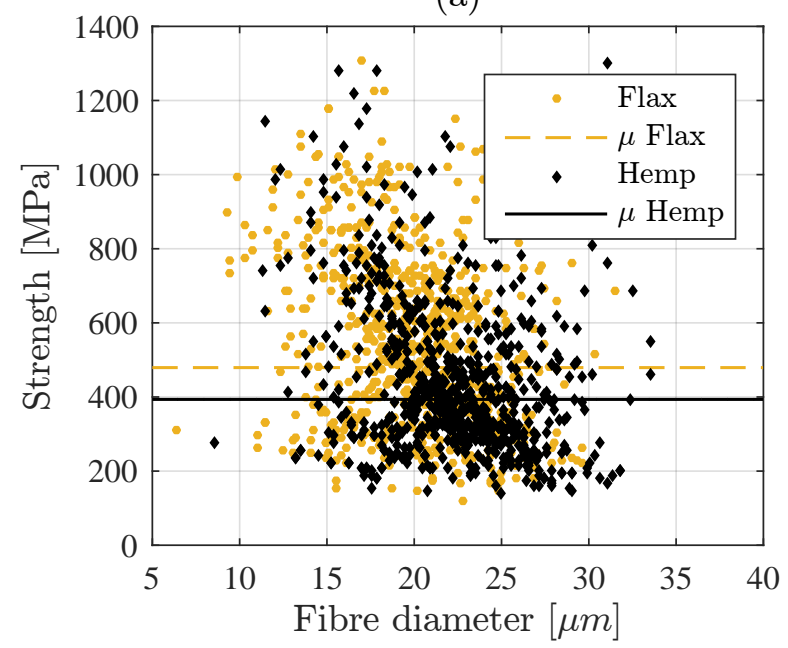

(b)

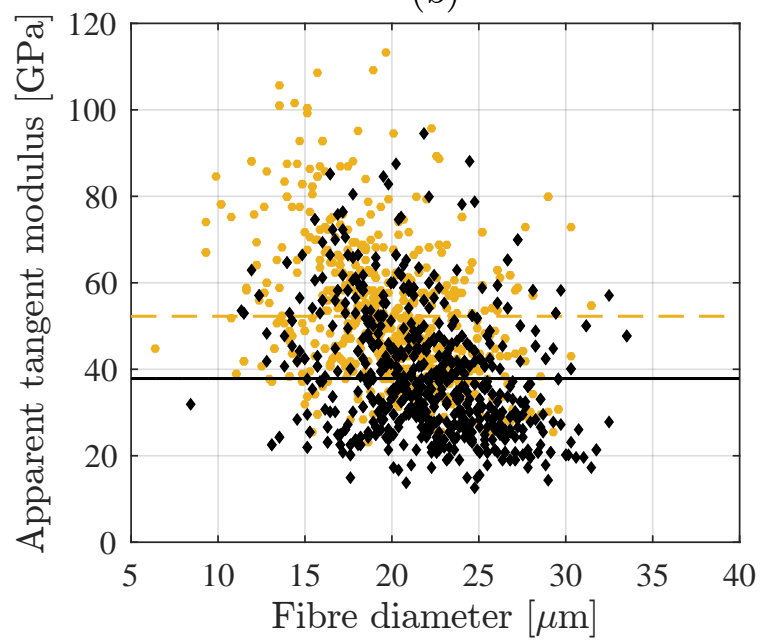

Fig. 12: Representation of the strength (a) and the initial apparent tangent modulus (b) as a function of the fibre diameter for flax and hemp. 


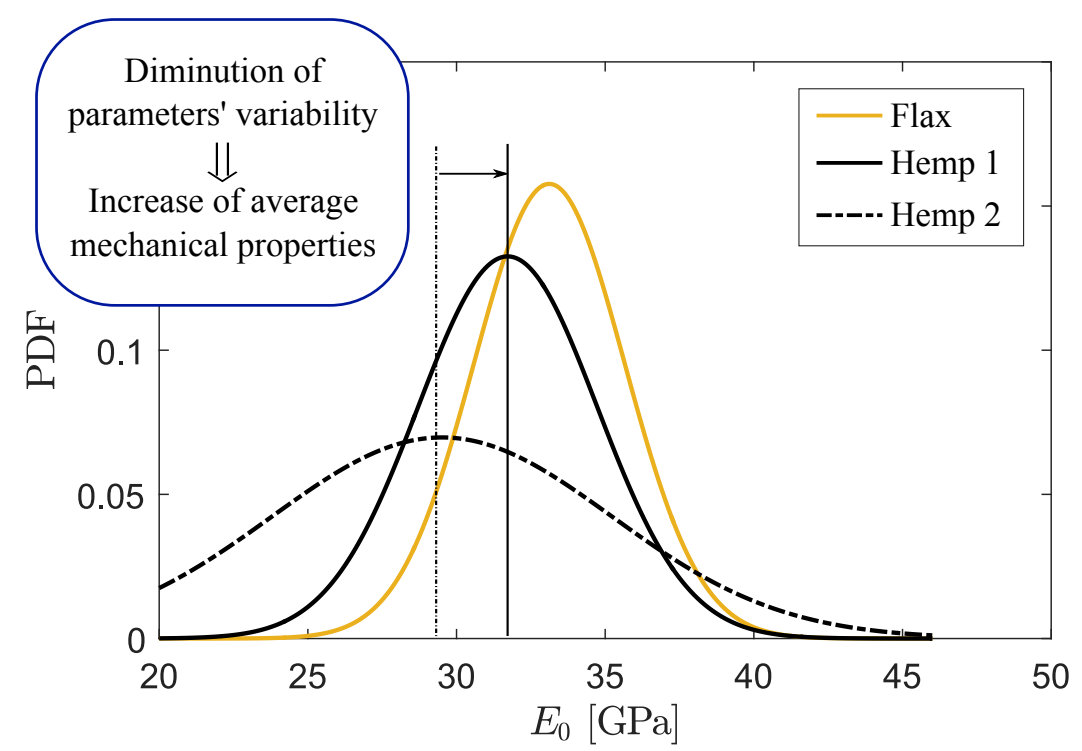

Fig. 13: Probability density functions of the initial apparent tangent modulus $\left(E_{0}\right)$ obtained for flax and hemp fibres using different level of variability of parameters. 
Table 1: Nominal values, standard-deviation and ranges of some morphological, ultrastructural and biochemical composition parameters for flax and hemp fibres.

\begin{tabular}{|c|c|c|c|c|c|c|c|c|}
\hline & \multicolumn{4}{|c|}{ Flax } & \multicolumn{3}{|c|}{ Hemp } & \multirow[b]{2}{*}{ Ref. } \\
\hline & Parameters & $\mu$ & $\sigma$ & Range & $\mu$ & $\sigma$ & Range & \\
\hline \multirow{3}{*}{ Morphology } & $\mathrm{D}[\mu m]$ & 19.9 & 5 & [13-26] & 25 & 10 & {$[10-50]$} & \multirow{3}{*}{$\begin{array}{l}{[50,13,12,51]} \\
{[52,53,54,11]}\end{array}$} \\
\hline & $\mathrm{d}[\mu m]$ & 5 & 2 & {$[3-8]$} & 4 & 1.5 & {$[1-10]$} & \\
\hline & $\mathrm{e}[/]$ & 0.2 & 0.1 & {$[0-0.3]$} & 0.3 & 0.1 & {$[0.05-0.4]$} & \\
\hline \multirow{3}{*}{$S_{2}$ layer } & $\psi\left[^{\circ}\right]$ & 10 & 3 & {$[6-11]$} & 8 & 3 & {$[1-15]$} & \multirow{3}{*}{$\begin{array}{r}{[55,56,57]} \\
{[23,22,58,20]}\end{array}$} \\
\hline & $m_{c}[\%]$ & 60 & 15 & {$[45-76]$} & 75 & 15 & {$[50-100]$} & \\
\hline & $m_{c r}[\%]$ & 95 & 5 & [90-100] & 65 & 13 & [40-90] & \\
\hline
\end{tabular}


Table 2: Nominal values, standard-deviation and ranges of viscoelastic and elastic parametrs used for the sensitivity analysis.

\begin{tabular}{|c|c|c|c|c|c|c|}
\hline & & Parameters & $\mu$ & $\sigma$ & Range & \multirow{7}{*}[59]{} \\
\hline \multirow{6}{*}{ Viscoelasticity } & & $n_{\text {inf }}$ & 0.406 & 0.0464 & {$[0.3735-0.4392]$} & \\
\hline & & $n_{0}$ & 2.544 & 2.423 & {$[0.8305-4.2575]$} & \\
\hline & & $\beta_{T} / E_{T}$ & 0.0372 & 0.0188 & {$[0.0239-0.0506]$} & \\
\hline & & $\beta_{L T} / G_{L T}$ & 0.0015 & $9.602 \mathrm{e}-04$ & [8.32e-04-0.00219] & \\
\hline & & $n_{\min }$ & 0.919 & 0.077 & [8.65e-01-0.974] & \\
\hline & & $n_{\max }$ & 0.742 & 0.0835 & {$[0.683-0.8011]$} & \\
\hline \multirow{18}{*}{ Elasticity } & & $E_{L}[\mathrm{GPa}]$ & 135 & 27 & {$[70-170]$} & \multirow{18}{*}{$\begin{array}{r}{[40,41,60]} \\
{[42,61]}\end{array}$} \\
\hline & Crystalline & $E_{T}[\mathrm{GPa}]$ & 27 & 5.4 & {$[20-34]$} & \\
\hline & Cellulose & $\nu_{L T}$ & 0.15 & 0.05 & {$[0.1-0.2]$} & \\
\hline & $(\mathrm{CC})$ & $G_{L T}[\mathrm{GPa}]$ & 4.5 & 0.9 & {$[3-6]$} & \\
\hline & & $\varrho\left[\mathrm{g} / \mathrm{cm}^{3}\right]$ & 1.6 & / & / & \\
\hline & Amornhous & $E[\mathrm{GPa}]$ & 8.5 & 1.7 & {$[5-15]$} & \\
\hline & Cellulose & $G[\mathrm{GPa}]$ & 4 & 0.8 & {$[1-7]$} & \\
\hline & $(\mathrm{AC})$ & $\nu$ & 0.2 & 0.05 & {$[0.1-0.3]$} & \\
\hline & (110) & $\varrho\left[\mathrm{g} / \mathrm{cm}^{3}\right]$ & 1.42 & / & / & \\
\hline & \multirow{5}{*}{$\begin{array}{c}\text { Hemicellulose } \\
\text { (HC) }\end{array}$} & $E_{L}[\mathrm{GPa}]$ & 7 & 1.4 & {$[5-9]$} & \\
\hline & & $E_{T}[\mathrm{GPa}]$ & 3.5 & 0.7 & {$[2-5]$} & \\
\hline & & $\nu_{L T}$ & 0.2 & 0.05 & {$[0.1-0.3]$} & \\
\hline & & $G_{L T}[\mathrm{GPa}]$ & 1.5 & 0.3 & {$[1-3]$} & \\
\hline & & $\varrho\left[\mathrm{g} / \mathrm{cm}^{3}\right]$ & 1.4 & l & / & \\
\hline & \multirow{4}{*}{$\begin{array}{l}\text { Lignin } \\
(\mathrm{LG})\end{array}$} & $E[\mathrm{GPa}]$ & 3 & 0.6 & {$[2-4]$} & \\
\hline & & $G[\mathrm{GPa}]$ & 0.7 & 0.14 & {$[0.4-1]$} & \\
\hline & & $\nu$ & 0.3 & 0.06 & {$[0.2-0.4]$} & \\
\hline & & $\varrho\left[\mathrm{g} / \mathrm{cm}^{3}\right]$ & 1.4 & / & / & \\
\hline
\end{tabular}


Table 3: Comparison between mechanical properties of flax and hemp reported in the literature and those obtained in this numerical study. Properties listed : initial apparent stiffness $E_{0}$, strength $\sigma_{r}$, strain at failure $\varepsilon_{r}$ and $\eta$ ratio. Data from the literature are from [25] on M1 (2009) for flax and [17] on Fedora 17 (2007) for hemp.

\begin{tabular}{lcc|cc} 
& \multicolumn{2}{c|}{ Flax } & \multicolumn{2}{c}{ Hemp } \\
\hline & Literature & This work & Literature & This work \\
\hline$E_{0}[\mathrm{GPa}]$ & $56.2 \pm 11.9$ & $52.3 \pm 15.8$ & $33.8 \pm 12.2$ & $37.9 \pm 13.0$ \\
$\sigma_{r}[\mathrm{MPa}]$ & $1197 \pm 452$ & $479 \pm 225.3$ & $489 \pm 233$ & $393.5 \pm 194.6$ \\
$\varepsilon_{r}[\%]$ & $2.2 \pm 0.7$ & $1.11 \pm 0.32$ & $2.5 \pm 1.3$ & $1.44 \pm 0.40$ \\
$\eta[/]$ & 0.27 & $0.43 \pm 0.11$ & {$[/]$} & $0.36 \pm 0.12$ \\
\hline
\end{tabular}

Table 4: Parameters of the power function $y=a x^{b}$ used to approximate the relationships between the $\eta$ ratio and strength of flax and hemp

\begin{tabular}{lcc} 
& $\mathrm{a}$ & $\mathrm{b}$ \\
\hline Flax & 158.9 & -1.195 \\
Hemp & 161.9 & -1.006 \\
\hline
\end{tabular}

Table 5: Means and standard deviations of fibre diameter $D$ and mass fraction of crystalline cellulose $m_{c r}$ used for simulations in Fig. 13. Results in terms of mean and standard deviation of initial apparent tangent modulus $E_{0}$.

\begin{tabular}{lcc|c} 
& $\mathrm{D}[\mu \mathrm{m}]$ & $m_{c r}[\%]$ & $E_{0}[\mathrm{GPa}]$ \\
\hline & $\mu \pm \sigma$ & $\mu \pm \sigma$ & $\mu \pm \sigma$ \\
\hline Flax & $19.9 \pm 5$ & $95 \pm 5$ & $33.12 \pm 2.53$ \\
Hemp 1 & $25 \pm 5$ & $65 \pm 5$ & $31.72 \pm 3.01$ \\
Hemp 2 & $25 \pm 10$ & $65 \pm 13$ & $29.51 \pm 5.72$ \\
\hline
\end{tabular}

